\title{
Gerenciamento do risco ocupacional no Exército Brasileiro: aspectos normativos e práticos
}

\author{
Occupational risk management in the Brazilian \\ army: normative and practical aspects
}

\author{
${ }_{1}^{1}$ Escola de Aperfeiçoamento \\ de Oficiais do Exército, \\ Rio de Janeiro, Brasil. \\ Correspondência \\ E. B. Neves \\ Escola de Aperfeiçoamento \\ de Oficiais do Exército. \\ Av. Duque de Caxias 2947, \\ bloco 6, apto. 101, \\ Rio de Janeiro, $R J$ \\ 21615-220, Brasil. \\ borbaneves@hotmail.com \\ borbaneves@ig.com.br
}

\begin{abstract}
This study aims to describe the risk management method used by the Brazilian Army, ranging from the guidelines, norms, and standards to the implementation of activities in the barracks, providing a brief comparison with key occupational safety provisions by the Ministry of Labor and Employment. A qualitative approach was used, based on triangulation of data collection techniques: document collection; systematic observation; and a semi-structured interview with 24 key informants among the military, divided into three groups, aimed at collecting information on the main hierarchical levels: officers, sergeants, corporals, and privates. We found that the Brazilian Army's risk management method is based on three main documents: Instruction Booklet 32/1, Instruction Booklet 32/2, and the Military Instruction Program. The method only refers to accident risks, overlooking other important aspects covered in the Regulatory Standards of the Ministry of Labor and Employment and other types of risks.
\end{abstract}

Risk; Safety Management; Occupational Health; Occupational Risks

\section{Introdução}

O militar convive com riscos durante toda a vida profissional. Seja nos treinamentos em tempo de paz, ou de guerra, a possibilidade iminente de um dano físico, ou da morte, é um fato permanente dessa profissão. Suas atribuições exigem elevado nível de saúde física e mental, não só por ocasião de eventuais conflitos, para os quais deve estar sempre preparado, como também no cotidiano da caserna.

Nas últimas décadas, principalmente na América do Norte e nos países da Europa, tem havido uma mudança substancial no enfoque dos profissionais que convivem diariamente com os riscos em seus locais de trabalho. Em vez de sistemas compensatórios e de fim de linha, busca-se enfatizar mais o aspecto preventivo, ou seja, atuar no controle e eliminação dos riscos na fonte, e não após a ocorrência de acidentes e doenças. A organização do trabalho e as práticas gerenciais passaram a ser reconhecidas como importante foco de análise, seja como causadoras de acidentes, doenças e sofrimento, ou como integrantes fundamentais das políticas de segurança e saúde nas empresas 1 .

No ambiente militar são comuns extensas jornadas de trabalho, problemas ergonômicos, exposição a agentes químicos, físicos e biológicos que, reconhecidamente, são considerados fatores de risco ocupacional para o trabalhador 2 . 
O conceito de risco é bidimensional, representando a possibilidade de um efeito adverso ou dano, a incerteza da ocorrência, a distribuição no tempo e a magnitude do resultado desfavorável. Assim, de acordo com essa definição, situação ou fator de risco é uma condição ou conjunto de circunstâncias que tem o potencial de causar um efeito adverso, que pode ser: morte, lesões, doenças ou danos à saúde e à propriedade ou ao meio ambiente 3 .

Classicamente, os fatores de risco para a saúde e segurança dos trabalhadores presentes ou relacionados ao trabalho, de acordo com a Organização Pan-Americana da Saúde no Brasil, podem ser classificados em cinco grandes grupos: físicos; biológicos; ergonômicos e psicossociais; químicos e de acidentes ${ }^{3}$.

Neste estudo procurou-se descrever o método de gerenciamento de risco que o Exército Brasileiro utiliza em suas atividades, abordando desde a parte normativa-documental até a execução das atividades nos quartéis de tropa e confrontá-lo, de maneira sucinta, com alguns aspectos de segurança ocupacional preconizados pelo Ministério do Trabalho e Emprego.

\section{Materiais e métodos}

O presente estudo caracteriza-se como descritivo e utilizou-se a abordagem qualitativa, em sua dimensão mais objetiva ${ }^{4}$. Foi possível uma aproximação da realidade com base em uma triangulação de técnicas de coleta de dados, a saber: coleta documental, observação sistemática e entrevista semi-estruturada.

A pesquisa foi realizada em cinco unidades de tropa do Exército Brasileiro. Realizou-se a observação sistemática com a freqüência de três vezes semanais, durante cinco meses, um mês em cada unidade pesquisada. A coleta documental foi realizada segundo a leitura e fichamento dos documentos que normatizam procedimentos gerais para todo o Exército e dos documentos específicos das unidades pesquisadas. As entrevistas foram do tipo semi-estruturada com roteiro único. A entrevista semi-estruturada é um instrumento que possibilita a coleta de informações objetivas, e mais do que isto, permite captar a subjetividade embutida em valores, atitudes e opiniões 5 .

Os informantes foram divididos em três grupos de militares, visando a coletar informações dos três grandes círculos hierárquicos do Exército: oficiais, sargentos, cabos e soldados, a saber: (1) Grupo I: oficiais dos diversos postos e com diferentes tempos de serviço; (2) Grupo II: sargentos com diferentes tempos de serviço; (3) Grupo
III: cabos ou soldados com diferentes tempos de serviço.

A seleção dos sujeitos foi balizada por indivíduos que tivessem atribuições de fiscalização, coordenação ou execução de atividades de instrução nas unidades pesquisadas. A amostragem utilizada, 24 sujeitos, distribuídos igualmente pelos grupos, é compatível com a pesquisa qualitativa e foi considerada suficiente, na medida em que a riqueza do material se mostrou adequada para os procedimentos metodológicos adotados e, além disso, os discursos se tornavam recorrentes, o que é denominado "ponto de redundância" 6 .

O estudo seguiu os aspectos éticos recomendados pela Resolução $n^{o}$. 196/96 sobre Pesquisa Envolvendo Seres Humanos e teve seu protocolo aprovado pelo Comitê de Ética em Pesquisa, Instituto de Estudos em Saúde Coletiva, Universidade Federal do Rio de Janeiro - CEP/IESC.

\section{Apresentação e discussão dos resultados}

A Portaria $n^{\circ}$. 3.214, de 08 de junho de 1978, regulamentou a Lei $n^{\circ}$. 6.514, de 22 de dezembro de 1977, que alterou o Capítulo V do Título II da Consolidação das Leis do Trabalho (CLT), instituindo as Normas Regulamentadoras (NR) sobre a atuação do governo, empregadores e empregados na prevenção de danos à saúde e segurança do trabalho. Dentre as NR, a NR-1 estabelece as disposições gerais sobre as NR, mencionando em seu subitem 1.1 que: as NR relativas à segurança e medicina do trabalho são de observância obrigatória pelas empresas privadas e públicas e pelos órgãos públicos de administração direta e indireta, bem como pelos órgãos dos poderes legislativo e judiciário que possuam empregados regidos pela CLT 7,8. Isso exclui os servidores militares da necessidade de observância das NR, pois estes têm suas relações trabalhistas regulamentadas pelo Estatuto dos Militares 9 , o que, de certa forma, diferencia a atenção à saúde ocupacional dos militares em relação aos demais trabalhadores.

O Comando de Operações Terrestres COTER implementou, no ano de 2002, um caderno a respeito de procedimentos gerais de prevenção de acidentes de instrução, o Caderno de Instrução 32/1: Prevenção de Acidentes de Instrução 10 . Esse documento é fundamentado em lições apreendidas, um sistema de relatórios de caráter voluntário e esporádico que tem por objetivo o envio de sugestões para o aprimoramento deste e de outros documentos normativos calcados em experiências bem sucedidas 11 . O 
planejamento do gerenciamento do risco deve ser elaborado e construído ouvindo os trabalhadores em seus locais de trabalho, de forma sistemática, para que se permita a construção de uma ferramenta adequada 1 .

No ano de 2005 foi implementado pelo Exército Brasileiro um método de gerenciamento de risco 12 , por meio de orientações constantes no Programa de Instrução Militar (PIM), elaborado pelo Comando de Operações Terrestres (COTER) 11. Esse método tem a finalidade de sistematizar procedimentos, responsabilidades e atribuições que propiciem o desenvolvimento e a execução de ações relacionadas à prevenção de acidentes na instrução e em outras atividades correlatas que envolvam o emprego dos meios orgânicos e/ou sob custódia do Exército Brasileiro. O PIM refere-se ao gerenciamento do risco como um método de trabalho, a ser executado durante o processo de planejamento, em qualquer nível, de modo a constituir-se em mais uma ferramenta de apoio ao processo decisório 11.

O método de gerenciamento de risco tem como principal objetivo transformar o risco inerente a uma determinada atividade em um índice numérico (grau de risco), por meio de formulários de avaliação do risco, facilitando a sua mensuração e permitindo que o militar, na função de comando, atue para minorá-lo, trabalhando no sentido da prevenção dos acidentes. Os formulários adotados estão colecionados no Caderno de Instrução 32/2: Gerenciamento de Risco Aplicado às Atividades Militares, divididos pelas 15 principais atividades de risco vivenciadas no ano de instrução. No entanto, sua aplicação abrange não somente o preparo operacional, mas também, as atividades concernentes ao emprego real da Força Terrestre. A utilização dos formulários de gerenciamento de risco do Caderno de Instrução 32/2 possui caráter obrigatório e deve ser objeto de supervisão por parte dos comandantes, chefes e diretores 12 .

A avaliação do risco, no método de gerenciamento do risco, consiste no preenchimento de um formulário específico para a atividade em questão, no qual são atribuídos valores a determinados indicadores que são somados e comparados com um intervalo de valores constante numa legenda, para avaliar o nível de risco. É previsto que esse procedimento deva ser executado por um grupo ou equipe, de modo a minimizar a influência de fatores pessoais e conjugar experiências diversas, concluindo com a elaboração de uma planilha que efetivamente represente a realidade para o comandante envolvido 12 .

Embora esse procedimento pareça minimizar distorções, pode ser pouco confiável na medida em que o responsável pela avaliação não possua a capacitação adequada, ou o instrumento não seja específico para o processo em questão. A influência dessa capacitação pôde ser percebida num estudo sobre riscos auditivos, no qual os pesquisadores observaram em entrevistas com militares que os sujeitos entrevistados não tinham nenhuma informação sobre os riscos auditivos causados pelo ruído de impacto dos armamentos utilizados, nem a maneira pela qual devem se proteger para evitar a perda auditiva 13 .

O PIM, no seu capítulo 16, prevenção de acidentes na instrução, traça como pressupostos básicos, dentre outros, os seguintes: (a) todos os acidentes podem e devem ser evitados; (b) a prevenção de acidentes de instrução faz parte das funções e responsabilidades dos comandantes, chefes e diretores, em todos os níveis ${ }^{11}$.

$\mathrm{O}$ trecho acima sugere que os militares teriam controle total sobre o desenrolar de todas as atividades de treinamento, e atribuem esta função aos responsáveis em cada nível. No entanto, não foi encontrado no sistema de ensino militar qualquer instrumento de capacitação relacionado ao campo da segurança do trabalho, nem mesmo referência ou orientação no sentido de estimular este aprendizado fora da instituição.

Os Cadernos de Instrução 32/1 e 32/2 foram elaborados baseando-se em lições apreendidas. Esse tipo de informação tem, por vezes, de percorrer uma extensa cadeia burocrática hierarquizada, sendo submetida a juízos de valor e podendo ter o seu curso interrompido antes da chegada ao COTER 11. Tal princípio de elaboração torna esses instrumentos inespecíficos, uma vez que não tiveram a participação sistemática e efetiva dos militares diretamente envolvidos no processo de trabalho ${ }^{14}$. O olhar do analista precisa levar em conta que a percepção dos trabalhadores sobre suas ações tem explicação em contingências da própria atividade, sobretudo nas pressões originadas pelo ambiente que explicam a variabilidade do trabalho 14 .

Ainda sobre o aspecto normativo-documental, o Diário Oficial da União de 20 de agosto de 1992 publicou a Portaria $n^{\circ} .05$ do Departamento Nacional de Segurança e Saúde do Trabalhador (DNSST), implantando a obrigatoriedade da elaboração de mapas de riscos pelas Comissões Internas de Prevenção de Acidentes (CIPAS), que em 1994 foi incorporado à NR-9 15. O mapa de risco apresenta, de forma gráfica, os riscos por tipo e intensidade, existentes no local de trabalho 16.

Nas unidades militares pesquisadas, não foi observada a existência de comissões similares às CIPA, nem mesmo de mapas de riscos nos ambientes de trabalho. Os efetivos de militares dessas unidades variavam de 227 a 999. Observou- 
se que em todos os quartéis havia um oficial de prevenção de acidentes designado, pelo comandante, em ato administrativo. Esse é um aspecto que marca o distanciamento entre o modelo de gerenciamento de risco do Exército e o adotado pelas empresas regidas pela CLT.

A exposição aos diversos fatores de risco dentro de um processo produtivo está diretamente relacionada às atitudes, ao nível de cuidados para minimização de riscos, à própria natureza do processo produtivo e ao ambiente, seja este o local de trabalho ou o ambiente do seu entorno 17. Embora a NR-06 determine aos empregadores a obrigação de fornecer gratuitamente o Equipamento de Proteção Individual (EPI) adequado ao risco 18, o Exército, por não tê-la como norma obrigatória, realiza atividades nas quais deixa o militar entregue aos próprios cuidados. Foi observado, e mais tarde confirmado pelos informantes do estudo, que as proteções auditiva e visual não eram distribuídas gratuitamente aos instruendos durante as instruções de tiro.

Nessas mesmas instruções, notou-se que alguns instruendos, como não possuíam um protetor auricular manufaturado, se preocupavam em prover algum tipo de proteção auditiva com algodão e até mesmo colocando estojos de munição vazios nos ouvidos. Esse comportamento coletivo faz com que não se sintam em risco, dando-lhes a sensação de proteção por meio de um mecanismo de adaptação coletiva ao risco ${ }^{19}$, o que lhes "garante" a possibilidade de permanecerem em suas atividades. Um procedimento diferente foi percebido em relação a militares que dirigiam veículos blindados de combate, que não tinham a preocupação em se proteger do elevado ruído emitido pelos motores desses carros.

Nenhum dos documentos militares pesquisados aborda a questão da distribuição gratuita de EPI, porém, o Caderno de Instrução 32/2 prevê que a falta da proteção auditiva na instrução é considerada como incremento ao grau de risco da atividade de tiro. Esse documento não recomenda proteção visual nessa atividade 12 .

Durante as entrevistas, pôde-se constatar que não era geral o conhecimento dos Cadernos de Instrução 32/1 e 32/2 por parte dos militares. Quando foram perguntados se conheciam tais documentos, surgiram respostas como: "Não, poucas vezes eu vi algum documento sobre isso ou que amarre alguma coisa em relação a isso!" e "Não, nunca ouvi falar". Mesmo aqueles que afirmavam conhecer esses documentos, quando perguntados se já haviam utilizado os formulários de gerenciamento do risco respondiam: “Não, nunca preenchi esse formulário" e "Não, nunca preenchi esses formulários, mas eu já vi companheiros preenchendo...".
Pôde-se perceber também, na observação sistemática e durante as entrevistas, que os equipamentos de proteção utilizados pelos militares restringem-se basicamente a: capacete balístico, colete à prova de tiro e, eventualmente, protetor auricular. Quando questionados sobre os equipamentos de proteção individual e quanto à adequação dos mesmos às atividades, respondiam da seguinte forma: "Só em missão real mesmo é que a gente tem que usar capacete e colete". "Sim, o capacete não atrapalha, mas é incomodo. Se eu pudesse, deixaria de usá-lo, mas o colete não!" e "A única situação em que a gente tem que usar algo assim é com relação àquele colete à prova de balas, que tem aquela placa de metal pesada e que tira um pouco da mobilidade do combatente. $O$ capacete balístico também, se não tiver bem ajustado, diminui uns $20 \%$ da operacionalidade do militar".

Quanto ao protetor auricular, só foi citado quando o entrevistador perguntou a respeito das instruções de tiro, obtendo respostas do tipo: "O equipamento de proteção que a gente usa é o capacete balístico e o protetor auricular..." e "O capacete balístico, praticamente fica por conta só do capacete...". Foi percebido que, no ambiente militar, o uso de EPI fica a cargo dos responsáveis pelas atividades e instruções.

Nos Estados Unidos, os ruídos de explosão causados pelos tiros de arma de fogo são uma das primeiras causas de perda auditiva induzida por ruído. Com o aumento dos esportes de tiro, um número maior de pessoas vem sofrendo de trauma acústico ou perda auditiva neurosensorial gradual secundária a ruídos excessivos de arma de fogo. A perda auditiva repentina resulta da pressão sonora elevada do ruído de impulso que excede o nível crítico, podendo causar lesões, mecânicas ou metabólicas, nas estruturas do ouvido interno. Já a perda auditiva gradual é resultado de exposição durante anos aos ruídos de impulso de arma de fogo que não são suficientemente altos para causar o trauma acústico, mas têm efeitos danosos, a longo prazo, às estruturas do ouvido interno 20.

Quanto à proteção visual, não foi percebida preocupação por parte dos militares em nenhuma atividade observada, nem foi encontrada qualquer normatização a respeito. Sabe-se, porém, que algumas atividades militares, como o salto de pára-quedas, podem provocar rompimentos, hemorragias ou até o deslocamento da retina e, portanto, torna-senecessária a utilização doóculos deproteção (OlhonoSalto.http://www. drvisao.com.br/ler_reportagem_1.php?id=1, acessado em 26/Set/2006). Segundo os informantes da própria tropa pára-quedista, esse equipamento não é distribuído nem tão pouco 
utilizado. Esse fato contribui para relatos como o que se segue: “...só no salto [de pára-quedas] já teve uns cinco caras que se acidentaram grave aqui, e desses, dois estão até hoje considerados incapaz pela junta [médica] e devem ser reformados. Teve ainda o caso de um soldado que ficou cego de um olho...". Ward \& Gorie 21 encontraram, durante seu estudo, como fatores de risco mais importantes à ocorrência de lesões nos olhos: a idade, história prévia de danos nos olhos nos últimos dois anos, e, paradoxalmente, a percepção que os supervisores estão preocupados e bem informaram sobre prevenção de danos nos olhos.

Um dos sujeitos entrevistados nesta pesquisa, que possui a formação em eletricista de autos, relatou que utilizou gasolina para limpeza de peças, sem luvas ou máscara, durante 14 anos. Acrescentou ainda que isso lhe foi ensinado durante a sua formação no Exército. Quanto à utilização do EPI, ele relatou que não o utilizava porque não havia material disponível. Embora não existam evidências sobre fatores de risco ocupacionais específicos entre militares e doenças do sistema nervoso, outras exposições também comuns ao ambiente de trabalho militar encontram-se associadas às neuropatias, como vários compostos metálicos, organoclorados, solventes e os campos eletromagnéticos 22 .

Um estudo com militares americanos, que serviram no período de guerra na Coréia, apresentou dados sugestivos de maior risco para as doenças do sistema nervoso nas ocupações de operação e reparos de equipamentos elétricos, eletrônicos e de comunicação ${ }^{23}$. Isso realça a importância do adequado controle da rotatividade dos militares que exercem tais atividades, porém, nada foi notado referente a essa questão no transcurso deste estudo.

Partindo-se para uma análise mais ampla, pôde-se verificar que o modelo de gerenciamento de risco adotado pelo Exército está apoiado em três principais documentos: o Caderno de Instrução 32/1; o Caderno de Instrução 32/2 e o PIM. Pode-se admitir, em tese, que as atividades que podem levar a lesões, quando de exposições prolongadas, tais como: emprego de equipamentos eletro-eletrônicos, exposição a ruídos de motores e manipulação de determinados produtos químicos como gasolina, não são consideradas como risco ocupacional pelos militares do Exército, uma vez que não existe normatização específica à prevenção das possíveis lesões causadas por estas atividades, nem mesmo a percepção deste risco por parte dos militares entrevistados. Mesmo nas atividades que possuem um formulário de gerenciamento de risco específico, não há nada que previna as exposições excessivas a fatores como ruídos elevados ou produtos químicos.

Mesmo que muitas das situações de risco pelas quais os trabalhadores passam sejam o resultado de suas decisões pessoais, o que não parece ser o caso dos militares do Exército, isto ultrapassa as fronteiras do individual e torna-se um problema de saúde coletiva, na medida em que se reflete na saúde de um grupo de trabalhadores 24 .

\section{Conclusão}

O Exército Brasileiro possui um método de gerenciamento do risco que se restringe ao gerenciamento dos riscos de acidentes, não direcionando atenção aos demais tipos de riscos: físicos; ergonômicos e psicossociais; biológicos e quími$\cos 3$. Percebe-se alguma atenção dispensada aos riscos de acidentes, que deram origem à própria normatização existente hoje no Exército 10, porém aos demais tipos de risco não foi percebida qualquer preocupação ou ação preventiva normatizada.

Apesar do Exército Brasileiro parecer considerar, de certa forma, a atividade pára-quedista como de risco elevado e diferenciado, pois prevê procedimentos específicos para instrução e um caráter voluntário para o ingresso nesta especialidade, o modo como a Instituição lida, reconhece e gerencia este risco não ratifica esta percepção. Mesmo em relação ao risco de acidentes, em atividades como pára-quedismo e tiro, pôde-se observar que ainda não há uma prevenção, em nível adequado, em relação aos riscos destas atividades. Tal fato pode mesmo estar relacionado à falta da percepção de risco por parte dos próprios militares, o que os leva a negligenciarem esta proteção e, conseqüentemente, não a normatizarem. Duarte Filho et al. 25, apontam algumas razões que contribuem para a manutenção dos problemas relacionados à segurança do trabalho, e a primeira delas é que as pessoas envolvidas com as condições ou fatores de risco não tinham a real percepção da existência dos mesmos. Não sabiam que aquela situação presente constituía risco potencial à integridade física e/ou mental dos trabalhadores, ou ainda ao patrimônio da empresa.

Considerando o grande efetivo do Exército Brasileiro, torna-se urgente medidas que mitiguem os riscos ocupacionais a que estão expostos esses trabalhadores. Assim, sugere-se um aprofundamento da discussão sobre os riscos laborais no Exército, que se justifica em função da natureza de algumas atividades, tais como: 
operações especiais em situação de guerra e teste de equipamentos militares, entre outras. Para as atividades que já possuem orientações conti- das nas NR do Ministério do Trabalho e Emprego, recomenda-se a adoção destas orientações pelos militares.

\section{Resumo}

Neste estudo procurou-se descrever o método de gerenciamento do risco que o Exército Brasileiro utiliza em suas atividades, desde a parte normativo-documental atéa execução das atividades nos quartéis de tropa e confrontá-lo, de maneira sucinta, com alguns aspectos de segurança ocupacional previstos pelo Ministério do Trabalho e Emprego. Foi utilizada uma abordagem qualitativa, com base em uma triangulação de técnicas de coleta de dados, a saber: coleta documental; observação sistemática e entrevista semi-estruturada, na qual selecionou-se 24 informantes militares, os quais foram divididos em três grupos, visando a coletar informações dos grandes círculos hierárquicos: oficiais, sargentos, cabos e soldados. Constatou-se que o método de gerenciamento do risco do Exército Brasileiro apóia-se em três documentos principais: $o$ Caderno de Instrução 32/1, $o$ Caderno de Instrução 32/2 e o Programa de Instrução Militar. Observou-se, ainda, que esse método faz referência apenas aos riscos de acidentes, desconsiderando alguns aspectos importantes previstos nas Normas Regulamentadoras do Ministério do Trabalho e Emprego e os demais tipos de riscos.

Risco; Gerenciamento de Segurança; Saúde do Trabalhador; Risco Ocupacionais 


\section{Referências}

1. Porto MFS. Análise de riscos nos locais de trabalho: conhecer para transformar. São Paulo: Kingraf; 2000.

2. Silva M, Santana VS. Ocupação e mortalidade na Marinha do Brasil. Rev Saúde Pública 2004; 38:70915.

3. Ministério da Saúde. Doenças relacionadas ao trabalho: manual de procedimentos para os serviços de saúde. Brasília: Ministério da Saúde; 2001. (Série A: normas e manuais técnicos 114).

4. Uchimura KY, Bosi MLM. Qualidade e subjetividade na avaliação de programas e serviços em saúde. Cad Saúde Pública 2002; 18:1561-9.

5. Minayo MCS. Teoria, método e criatividade. Petrópolis: Editora Vozes; 1995

6. Lincoln YS, Guba EG. Naturalistic inquiry. Beverly Hills: Sage Publications; 1985.

7. Brasil. Portaria $\mathrm{n}^{\circ}$. 3.214, de 8 de junho de 1978 Aprova as Normas Regulamentadoras - NR - do Capítulo V, Título II, da Consolidação das Leis do Trabalho, relativas à Segurança e Medicina do Trabalho. Diário Oficial da União 1978; 6 jul.

8. Brasil. Lei $n^{\circ}$. 6.514, de 22 de dezembro de 1977 . Altera o Capítulo V, do Título II, da Consolidação das Leis do Trabalho, relativo à Segurança e Medicina do Trabalho. Diário Oficial da União 1977; 23 dez.

9. Brasil. Lei no. 6.880, de 9 de dezembro de 1980 Dispõe sobre o Estatuto dos Militares. Diário Oficial da União 1980; 11 dez.

10. Comando de Operações Terrestres. Caderno de Instrução CI 32/1: Prevenção de acidentes na instrução. 1ạ Ed. Brasília: Estabelecimento General Gustavo Cordeiro de Farias; 2002.

11. Comando de Operações Terrestres. Programa de Instrução Militar - PIM. http://www.coter.eb.mil. br/pim.asp (acessado em 24/Fev/2006).

12. Comando de Operações Terrestres. Caderno de Instrução CI 32/2: gerenciamento de risco aplicado às atividades militares. 1a Ed. Brasília: Estabelecimento General Gustavo Cordeiro de Farias; 2005.

13. Silva AP, Costa EA, Rodrigues SMM, Souza Humberto LR, Massafera VG. Audiometric assessment for military personnel. Rev Bras Otorrinolaringol 2004; 70:344-50.
14. Almeida IM. A gestão cognitiva da atividade e a análise de acidentes do trabalho. Revista Brasileira de Medicina do Trabalho 2004; 2:275-82.

15. Brasil. Portaria ${ }^{\circ}$. 05, de 17 de agosto de 1992 . Altera a Norma Regulamentadora $n^{\circ} .9$, estabelecendo a obrigatoriedade de elaboração do mapa de riscos ambientais. Diário Oficial da União 1992; 20 ago.

16. Sivieri LH. Saúde no trabalho e mapeamento dos riscos. In: Sivieri LH, organizador. Saúde, meio ambiente e condições de trabalho: conteúdos básicos para uma ação sindical. São Paulo: Central Única dos Trabalhadores/Fundação Jorge Duprat Figueiredo de Segurança e Medicina no Trabalho; 1995. p. 75-111.

17. Gomide M, Serrão MA. A educação ambiental e a promoção da saúde. Cad Saúde Coletiva 2004; 12:69-86.

18. Brasil. Portaria ${ }^{\circ}$. 25, de 15 de outubro de 2001. NR 6 - estabelece as disposições legais relativas aos EPIs. Diário Oficial da União 2001; 17 out.

19. Guivant JS. Percepção dos olericultores da grande Florianópolis (SC) sobre os riscos decorrentes do uso de agrotóxicos. Rev Bras Saúde Ocup 1994; 22:47-57.

20. Stewart M, Pankiw R, Lehman ME, Simpson TH. Hearing loss and hearing handicap in users of recreational firearms. J Am Acad Audiol 2002; 13:1608.

21. Ward DL, Gorie C. Occupational eye injuries in soldiers. J Occup Med; 1991 33:646-50.

22. Axelson O. Neuroepidemiologia professional. In: Organización Internacional del Trabajo, editor. Enciclopédia de salud y seguridad en el trabajo. v. I. Madrid: Ministerio de Trabajo y Asuntos Sociales; 2001. p. 7.26-8.

23. Robinette CD, Silverman C, Jablon S. Effects upon health of occupational exposure to microwave radiation (radar). Am J Epidemiol 1980; 112:39-53.

24. Gomide M. Pesticide: how can it named? Ciênc Saúde Coletiva 2005; 10:1047-54.

26. Duarte Filho E, Oliveira JC, Lima DA. A redução e eliminação da nocividade do trabalho pela gestão integrada de saúde, meio ambiente e qualidade. In: Mendes R, organizador. Patologia do trabalho. v. 2. São Paulo: Editora Atheneu; 2005. p.1806-15.

Recebido em 28/Set/2006

Versão final reapresentada em 13/Mar/2007 Aprovado em 19/Mar/2007 